05

\title{
Влияние ультрафиолетового облучения на деформационные свойства синдиотактического 1,2-полибутадиена: роль окисления
}

\author{
() Ю.А. Лебедев, ${ }^{1}$ Р.Р. Кинзябулатов, ${ }^{1}$ В.В. Астанин, ${ }^{2}$ Д.В. Гундеров ${ }^{1,2}$ \\ ${ }^{1}$ Институт фризики молекул и кристаллов - обособленное структурное подразделение \\ Уфимского федерального исследовательского центра РАН, \\ 450075 Уфра, Россия \\ 2 Уфримский государственный авиационный технический университет, \\ 450000 Уфра, Россия \\ e-mail: kinzyabulatovrr@mail.ru
}

(Поступило в Редакцию 28 апреля 2018 г.)

\begin{abstract}
Исследованы влияние ультрафиолетового облучения на деформационные характеристики при одноосном растяжении и фотоиндуцированные изменения молекулярного строения синдиотактического 1,2полибутадиена - полимера, обладающего свойствами термоэластопласта. Для образцов, деформированных в условиях простого одноосного растяжения, получены кривые напряжение-деформация при различных временах облучения, и проанализированы особенности влияния УФ-облучения на деформационное поведение полимера. Установлено, что длительное облучение УФ-светом приводит к заметному упрочнению полимера - возрастанию модуля упругости, увеличению предела текучести и снижению степени деформации до разрыва. При этом наблюдается резкое возрастание молекулярной массы полимера и его сильное окисление, наиболее интенсивное в приповерхностном слое. Обсуждены механизмы межмолекулярного сшивания с одновременным окислением макромолекул при УФ-облучении и роль этих процессов в эволюции физикомеханических свойств под действием УФ-света.
\end{abstract}

DOI: $10.21883 / J T F .2019 .04 .47306 .174-18$

\section{Введение}

Сочетание свойств, присущих одновременно и термопластам (размягчение при повышенных температурах) и резинам (эластичность при комнатных температуpax), делает термопластичные эластомеры (ТЭП) чрезвычайно перспективным функциональным материалом для замещения обычных вулканизированных каучуков в некоторых применениях, где переработка полимерного материала является критическим требованием $[1,2]$. В отличие от термореактивной резины в пространственной полимерной сетке ТЭП поперечные связи имеют только физическую природу и являются обратимыми. Так что термопластичные эластомеры являются двухфазными материалами; одна из двух микроскопических фаз - аморфная и легко деформируемая, а вторая жесткая, „сшитая физически“, выполняющая функцию связи между эластичными блоками. Примерами могут служить микродомены агрегированных стирольных сегментов как в бутадиен-стирольном блок-сополимере [2] или ионные группы, привитые к основной неполярной полимерной цепи в иономерах [3], либо кристаллиты, образованные кристаллизацией цепных сегментов длинноцепочечных молекул, как например, в синдиотактическом 1,2-полибутадиене (СПБ) [4]. Отличаем последнего полимера от большинства других термоэластопластов является довольно простое строение линейная основная цепь $\left(\mathrm{CH}-\mathrm{CH}_{2}\right)_{n}$ с чередующимися слева и справа боковыми винильными группами $-\mathrm{CH}=\mathrm{CH}_{2}-[5]$. Содержание кристаллической фазы за- висит от стереорегулярности макромолекулярной цепи и может достигать $85-90 \%$ [6,7]. Это своеобразное „армирование“ аморфного полимера нанокристаллитами и придает данному полимеру свойства термоэластопласта. Регулируя в условиях синтеза степень кристалличности, можно в широких пределах менять строение СПБ и, следовательно, спектр его физико-механических свойств.

Кроме этого, наличие винильных высокореактивных связей в СПБ позволяет использовать и другие методы управления его строением и свойствами, а именно облучение ионизирующим излучением. Ранее было установлено, что основными процессами при облучении СПБ $\gamma$ - и электронными лучами $[8,9]$ и термическом воздействии [10] являются сшивание и окисление полимера по радикальным механизмам с образованием различных поперечных связей. Очевидно, что сходные процессы должны иметь место и при облучении СПБ-светом ультрафиолетового (УФ) диапазона длин волн, так как именно в этой области винильные связи наиболее интенсивно поглощают свет в результате $\pi \rightarrow \pi^{*}$ электронных переходов [11]. Благодаря высокой реакционной способности в условиях интенсивного УФ-облучения СПЬ нашел применение в области фотопечати, в качестве сшивающего агента [12]. В [13] на примере СПБ с синдиотактичностью $53 \%$ и степенью кристалличности $14 \%$ было показано, что УФ-облучение сопровождается заметным изменением упругопластичных характеристик данного полимера. Целью настоящей работы являлось дальнейшее изучение особенностей влияния УФ-света на 
физико-механические свойства СПБ с бо́льшей кристалличностью $(\sim 30 \%)$.

\section{Образцы для исследования и методика эксперимента}

В качестве объекта исследований использовали СПБ марки RB830 (JSR Corp., Япония) со среднечисловой молекулярной массой $M_{n} \sim 1.2 \cdot 10^{5}$, содержанием 1,2 звеньев $93 \%$, синдиотактичностью $\sim 85-90 \%$ и степенью кристалличности около $30 \%$ [4]. В отличие от СПБ, изученного в [13], RB830 имеет более линейные макромолекулы, поскольку характеризуется высокой степенью синдиотактичности и сравнительно небольшим количеством побочных звеньев 1,4-присоединения.

Облучение образцов проводили на расстоянии $1 \mathrm{~m}$ ртутными лампами ДРТ-250 в комбинации со светофильтром УФС-1 $\left(\lambda_{\max } \sim 330 \mathrm{~nm}\right)-$ на механических испытаниях и ДРШ-100 - во всех остальных случаях. Мощность излучения на поверхности образцов измеряли УФ-радиометром ТКА-ПКМ/13. При механических испытаниях она составляла $200 \mathrm{~W} / \mathrm{m}^{2}$, во всех остальных случаях $-40 \mathrm{~W} / \mathrm{m}^{2}\left( \pm 1 \mathrm{~W} / \mathrm{m}^{2}\right)$. Для уменьшения побочного ИК-излучения перед лампами устанавливали наполненные дистиллированной водой и термостатируемые кварцевые кюветы. Для регистрации электронных спектров поглощения использовался двухлучевой спектрометр SHIMADZU UV-3600 (Япония).

Для определения механических свойств использовали образцы в виде стандартных двусторонних лопаток с рабочей частью $2.5 \times 10 \mathrm{~mm}$ и толщиной $1.0 \pm 0.2 \mathrm{~mm}$ (в соответствии с размерами II типа ГОСТ 270-75), которые получали вальцево-прессовочным методом при $90^{\circ} \mathrm{C}$. Одноосное растяжение с постоянной скоростью $1.4 \cdot 10^{-3} \mathrm{~m} / \mathrm{s}$ проводили на испытательной машине ZM-40 (Германия) при температуре $20 \pm 5^{\circ} \mathrm{C}$.

Рентгеновские фотоэлектронные спектры (РФЭС) были получены с использованием спектрометра JPS-9010MX (Jeol Ltd., Japan), оснащенного монохроматическим источником рентгеновского излучения $\mathrm{AlK}_{\alpha}(h v=1456.6 \mathrm{eV})$ с ускоряющим напряжением до $12 \mathrm{kV}$ и током до $50 \mathrm{~mA}$. Участки характеристических спектров атомов O1s и $\mathrm{C} 1 \mathrm{~s}$ записывались при энергии пропускания анализатора $30 \mathrm{eV}$; полный спектр от 1000 до $0 \mathrm{eV}$, включающий все характеристические линии, регистрировался при энергии пропускания анализатоpa $50 \mathrm{eV}$. Калибровка шкалы энергий связи $\left(E_{b i n d}\right)$ производилась методом внутреннего стандарта по линии C1s углерода $\left(E_{b i n d}=284.80 \mathrm{eV}\right)$. Относительные концентрации элементов в зоне анализа (глубина зоны анализа $3-5 \mathrm{~nm}$ ) определялись на основании интегральных интенсивностей РФЭС-линий с учетом сечения фотоионизации соответствующих термов [14]. Для детального анализа использовалось разложение спектров на индивидуальные составляющие: после вычитания фона по методу Ширли [15] экспериментальная кривая раскладыва- лась на ряд линий, соответствующих фотоэмиссии электронов из атомов в различном химическом окружении; форма пиков аппроксимировалась функцией Гаусса. Измерение и обработка данных производилась с помощью встроенного пакета программ SpecSurf (Jeol Ltd., Japan).

\section{Физико-механические свойства СПБ и фотохимические превращения под действием УФ-облучения}

Рассмотрим влияние УФ-облучения на физикомеханические свойства СПБ JSR RB830. На рис. 1 представлены деформационные кривые в виде зависимости напряжения от удлинения $(\sigma-\varepsilon)$, полученные при растяжении образцов СПБ без облучения (рис. 1, $a$, кривая 1) и после облучения УФ-светом (рис. 1, $a$, кривые 2-4). Деформационное поведение исходного образца СПБ хорошо согласуется с литературными данными и является типичным для эластомеров (рис. $1, a$, кривая 1): упругая деформация образца продолжается почти до величины удлинения $\varepsilon \sim 25 \%$, а предел текучести составляет $\sim 8 \mathrm{MPa}$; диапазон вынужденной эластичности лежит в пределах $\varepsilon \sim 100-600 \%$, когда полимер ведет себя подобно каучуку, а природа такой высокой эластичности связана с распрямлением под влиянием нагрузки свернутых гибких полимерных цепей и переориентацией кристаллитов.

В области 600-650\% образец СПБ теряет прозрачность и приобретает молочно-белую окраску (так называемый крэйзинг), что приводит к повышению коэффициента упрочнения при дальнейшем росте деформации до разрушении [16]. Разрыв образца происходит при удлинении до $700 \%$ и напряжении $\sim 20 \mathrm{MPa}$ (предел прочности) через образование и слияние эллипсоидальных микропор (рис. 1,b).

Воздействие на образцы СПБ УФ-излучения в течение 60 min приводит к росту предела текучести полимера и снижению степени деформации до разрыва с $\sim 700$ до 630\% (рис. 1, $a$, кривая 2). Молекулярная масса СПБ за $60 \mathrm{~min}$ воздействия УФ-света увеличилась примерно в 1.5 раза, а при дальнейшем облучении полимер утрачивает способность растворяться в органических растворителях. Такое поведение, очевидно, связано с интенсивным межмолекулярным сшиванием и одновременным окислением макромолекул при УФ-облучении, что характерно для большинства карбоцепных полимеров [17].

Более длительное облучение УФ-светом приводит к уже заметному упрочнению полимера, причем чем дольше образец подвергается облучению, тем больше возрастает его предел текучести (с $\sim 8 \mathrm{MPa} \mathrm{у} \mathrm{необлу-}$ ченного образца до $\sim 10 \mathrm{MPa} \mathrm{у} \mathrm{полимера,} \mathrm{облученного}$ в течение $180 \mathrm{~min}$ ). Рост предела текучести объясняется существенным затруднением перестройки конформации макромолекул из-за фотосшивки СПБ. При этом заметно снижается удлинение до разрыва образца (до $\sim 400 \%$ для 180 min облучения). На микрофотографии (рис. 1,c) 

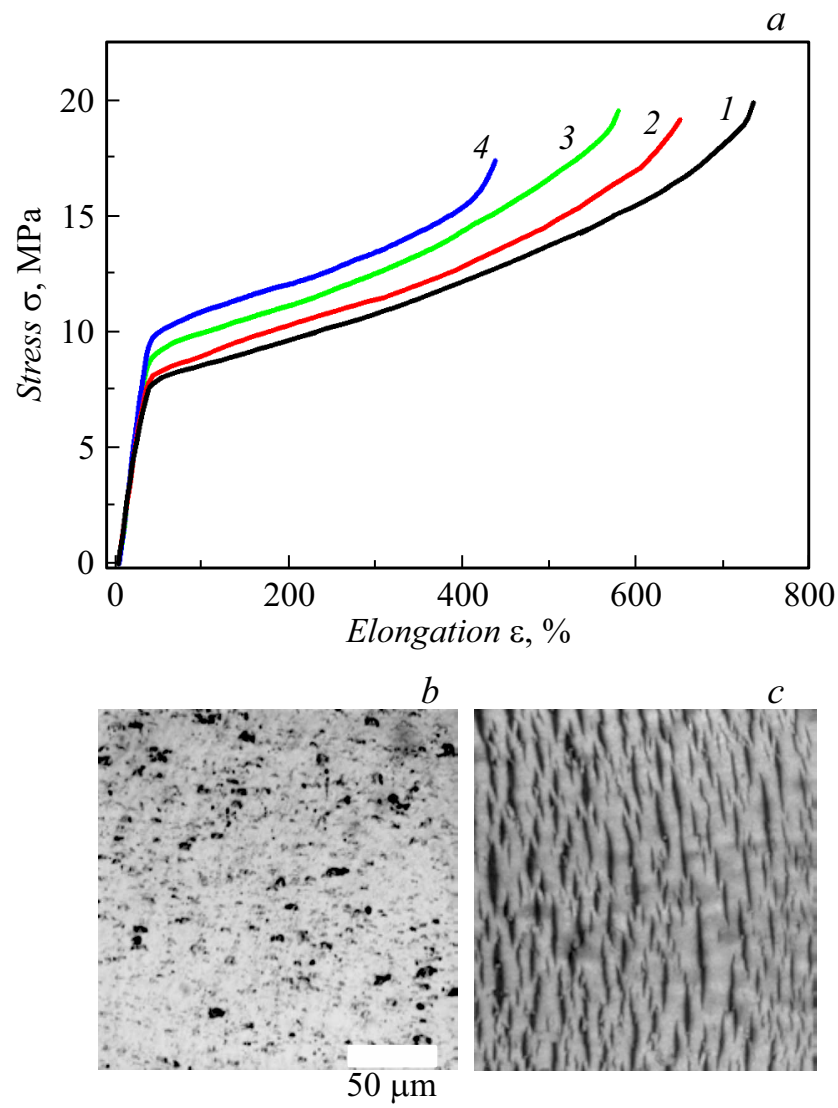

Рис. 1. $a-$ деформационные кривые $(\sigma-\varepsilon)$ образцов СПБ: 1 - исходный, 2 - облученный УФ-светом в течение $60 \mathrm{~min}$, 3 - в течение $120 \mathrm{~min}, 4$ - в течение $180 \mathrm{~min}$; и микрофотографии СПБ: $b-$ исходный образец после растяжения; $c$ СПБ облученный УФ-светом $180 \mathrm{~min}$ после растяжения.

хорошо видно образование при растяжении большого числа поперечных трещин клиновидной формы, что обусловлено затруднением необходимой перестройки структуры полимера под влиянием нагрузки. В результате их интенсивного развития и происходит разрыв облученного образца.

Образование поперечных сшивок между макромолекулами в полимере легко детектируется методом абсорбционной спектроскопии. При облучении пленок СПБ на воздухе, наряду с уменьшением поглощения в области винильных связей $(\lambda<210 \mathrm{~nm})$ и общим увеличением поглощения в области 210-400 nm (рис. 2), на УФспектрах наблюдается интенсивный рост двух полос поглощения при 215 и $250 \mathrm{~nm}$ (рис. 2, вставка), которые, как считается, связаны с появлением сопряженных структур $[18,19]$. После разложения УФ-спектров на компоненты становится очевидным присутствие в них еще одной интенсивной полосы при $230 \mathrm{~nm}$ (вставка на рис. 2), связанной с образованием кислородосодержащих групп (карбонильных и/или карбоксильных). Кроме того, на производных разностных спектрах поглощения заметны слабые полосы при 315 и $365 \mathrm{~nm}$, которые также могут быть отнесены к карбонилам. Скорости роста количества диеновых $(215 \mathrm{~nm})$ и триеновых $(250 \mathrm{~nm})$ структур и образования карбонильных групп $(230 \mathrm{~nm})$ велики в течение $t_{u v}=2 \mathrm{~h}$, затем они уменьшаются практически до нуля, так что концентрация этих структур достигает критической величины через $t_{u v}=2 \mathrm{~h}$ и дальше не меняется.

Для более детальной характеристики природы кислородсодержащих групп, индуцированных при УФоблучении, проведен анализ химического состава исходного и облученного образцов с использованием РФЭС. Обзорные фотоэлектронные спектры исходной и облученной в течение $6 \mathrm{~h}$ пленки СПБ приведены на рис. 3 (кривые 1 и 2). В спектрах РФЭС исследованных образцов обнаружены линии, соответствующие атомам С и О. Относительные атомные концентрации соответствующих элементов, определенные на основании данных РФЭС, приведены в таблице. Эти данные и обзорные спектры показывают, что экспозиция в УФ-свете существенным образом влияет на состав образца. Как можно было ожидать, углерод $(C 1 s$, линия при $\sim 285.0 \mathrm{eV})$ является основным компонентом исходного образца СПБ (рис. 3, кривая 1). Интенсивность соответствующего пика уменьшается в результате облучения (рис. 3, кривая 2), но остается вполне существенной составляющей по сравнению с другими элементами. Кислород, характеристическая линия $O 1 s$ которого расположена вблизи $\sim 533.0 \mathrm{eV}$, присутствует в исходном СПБ, но в незначительной концентрации (см. таблицу). Интенсивность этого пика увеличивается после облучения и

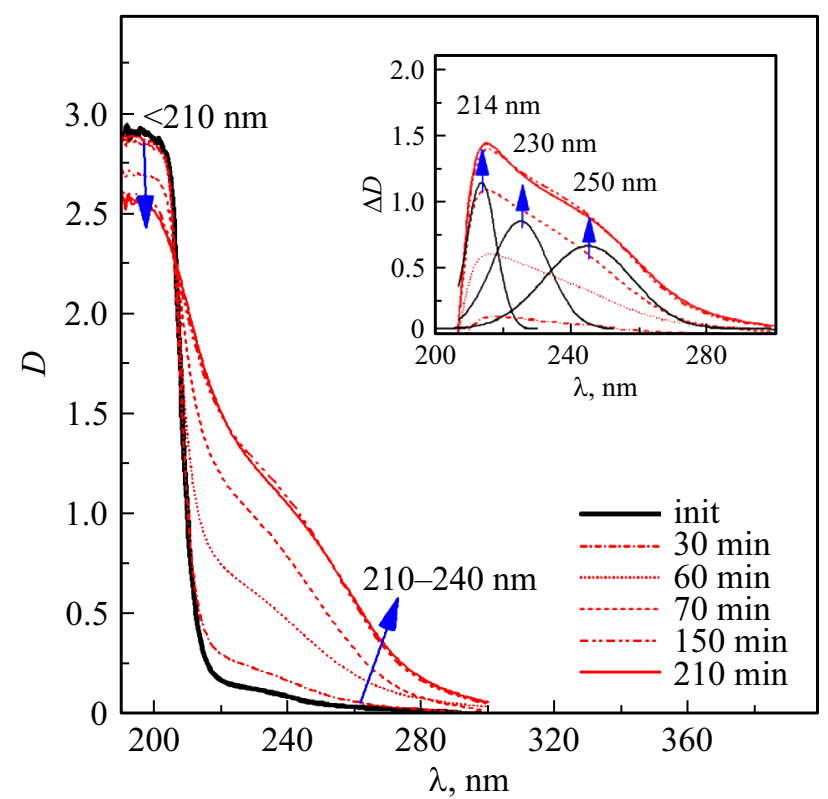

Рис. 2. Электронные спектры поглощения пленки СПБ (-) толщиной $10 \mu \mathrm{m}$ в процессе УФ-облучения на воздухе (-). На вставке - разностный спектр поглощения пленки $\Delta D=D_{t}-D_{0 \min }$. Стрелками обозначено увеличение $(\uparrow)$ и уменьшение $(\downarrow)$ интенсивности сигналов и спектральный состав разностных спектров поглощения. 


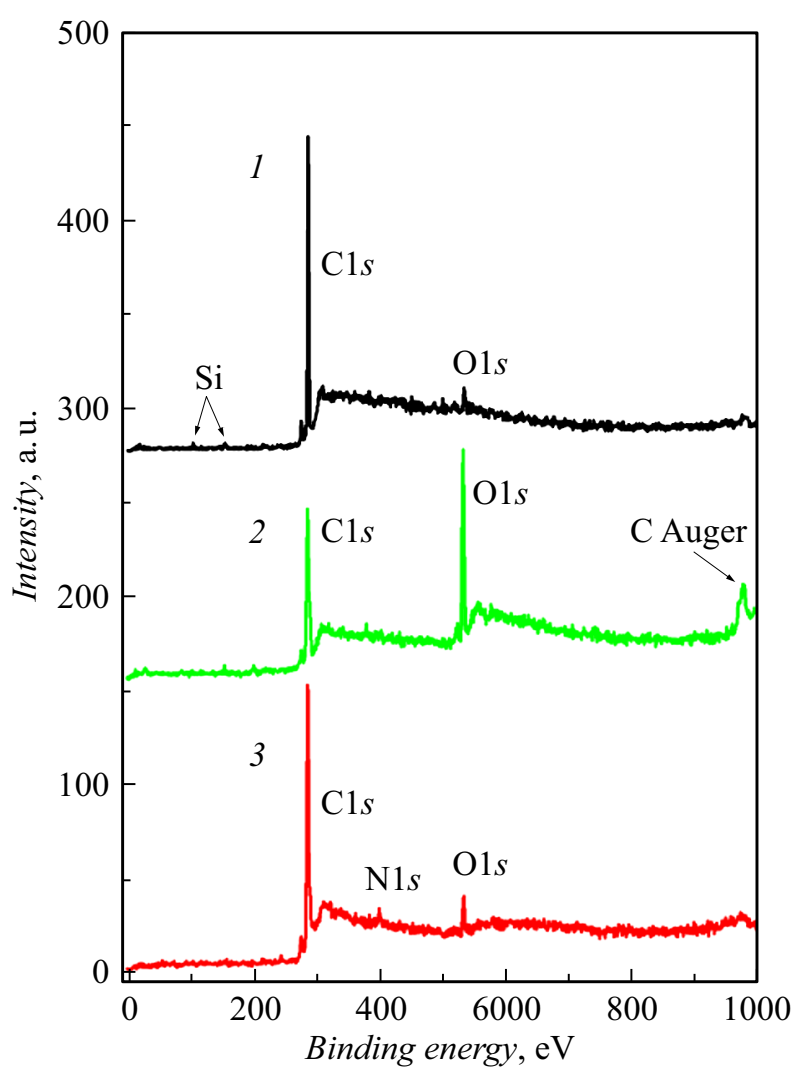

Рис. 3. Рентгеновские фотоэлектронные спектры образцов СПБ: 1 - исходный полимер, 2 - после облучения в воздухе в течение 6 h, 3 - после „травления“ образца 2 для удаления тонкого поверхностного слоя.

Элементный состав пленки СПБ

\begin{tabular}{l|c|c|c}
\hline \multicolumn{1}{c|}{ Образец/элемент } & $\mathrm{C}, \%$ & $\mathrm{O}, \%$ & $\mathrm{O} / \mathrm{C}$ \\
\hline Исходный & 95.5 & 4.5 & 0.047 \\
Облученный $(6 \mathrm{~h})$ & 66.5 & 33.5 & 0.504 \\
Облученный $(6 \mathrm{~h})$ & 92.7 & 7.3 & 0.079 \\
без приповерхностного слоя & &
\end{tabular}

становится сравнимой с интенсивностью линии $C 1 s$. На обзорных спектрах можно также детектировать наличие слабых пиков, расположенных на $\sim 105,152$ и 398, и отвечающих примесям других элементов - кремния (Si2p, $\mathrm{Si} 2 \mathrm{~s})$ и азота (N1s) соответственно. Присутствие примесей кремния и азота является естественным следствием процедур синтеза полимера, но основное „загрязнение“ поверхности связано по существу с кислородом.

Сравнивая кривые 2 и 3 на рис. 3 (и данные таблицы), можно заключить, что в поверхностном слое облученной пленки СПБ имеется гораздо более высокая концентрация кислорода, чем внутри ее. На поверхности образца, облученного в течение $6 \mathrm{~h}$, имеется до $33 \%$ кислорода, тогда как в объеме пленки содержание кислорода составляет всего $\sim 8 \%$, но почти вдвое превышает содержание кислорода в исходной необлученной пленке полимера. Эти данные позволяют сделать вывод, что во время облучения на поверхности пленки формируется тонкий сильно окисленный слой. Как известно [19], подобный приповерхностный окисленный слой имеет более чем на два порядка меньшую проницаемость для кислорода, чем не окисленный полимер. Так что образование этой сильно окисленной слабопроницаемой „корки“ на поверхности значительно затрудняет перенос кислорода в объем пленки СПБ, и степень окисления в объеме пленки соответственно намного ниже, чем на ее поверхности (см. таблицу). Анализ линий фотоэлектронов, связанных с C1s и O1s, позволяет улучшить понимание реакционных механизмов, ответственных за окисление СПБ при УФ-облучении. На рис. 4, $a$ представлены спектры высокого разрешения $\mathrm{C} 1 \mathrm{~s}$ исследованных образцов. Поскольку основным состоянием атомов углерода в данном полимере есть $\mathrm{C}-\mathrm{C}-$ и $\mathrm{C}-\mathrm{H}-$ связи, главным компонентом спектра необлученного СПБ является интенсивный пик в районе $285.0 \mathrm{eV}$ (рис. 4, $a$, кривая 1).

После облучения в течение $6 \mathrm{~h}$ в спектре появляется два новых пика при 286.7 и $288.7 \mathrm{eV}$, которые можно отнести к атомам углерода, связанным с одним $(\mathrm{C}-\mathrm{O})$ и двумя $(\mathrm{O}=\mathrm{C}-\mathrm{O})$ атомами кислорода (рис. $4, a$, кривая 2), а интегральная интенсивность пика $\mathrm{C} 1 \mathrm{~s}$ уменьшается почти вдвое. А именно после облучения происходит интенсивное окисление образца, которое начинается с поверхности, и образование различных кислородсодержащих групп (карбоксильных, кетонных и/или спиртовых). Аналогичное разложение спектральной линии на компоненты проведено и для спектров O1s исследованных образцов (рис. $4, b$ ). Здесь линия O1s может быть разложена на две составляющие, отвечающие энергии связи 532.2 и $533.7 \mathrm{eV}$, которые могут быть отнесены к $\mathrm{O}=\mathrm{C}-$ и $\mathrm{O}-\mathrm{C}$-связям соответственно. При облучении интенсивность пика O1s резко возрастает (рис. $4, b$, кривая 2). Однако удаление приповерхностного слоя методом ионного травления и анализ соответствующих спектров (рис. 4, кривые 3) подтверждает сделанный выше вывод о более слабом окислении внутреннего объема пленки полимера по сравнению с приповерхностными слоями.

Как известно, упругие модули окисленного слоя могут превышать соответствующие модули не окисленного полимера на 2-3 порядка [20]. Возникновение окисленного поверхностного слоя, имеющего низкую пластичность и являющегося достаточно хрупким, и ответственно за появление поперечных трещин (рис. 1,c) при растяжении облученных образцов. Отметим, что трещины равномерно покрывают большую область рабочей части образца. Причем эти трещины являются поверхностными и быстрее развиваются именно вдоль поверхности (в ином случае появление первых же „глубоких“ трещин привело бы к локализации деформации и разрушению (разрыву) образца). В то время как приповерхностный хрупкий слой уже начинает разрушаться, внутренние слои полимера продолжают деформироваться подобно 

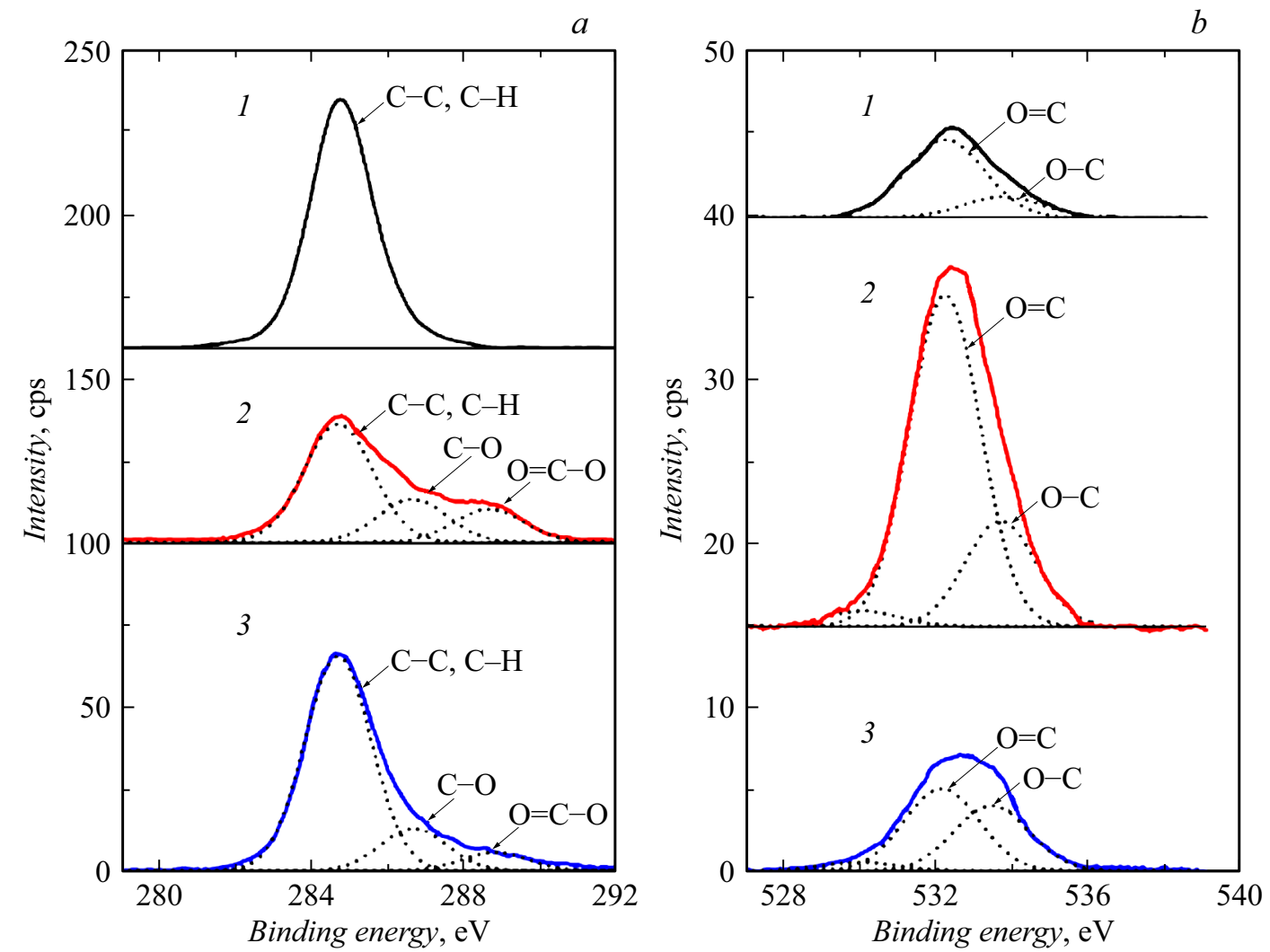

Рис. 4. Спектры $\mathrm{C} 1 s(a)$ и $\mathrm{O} 1 s(b)$ образцов СПБ: 1 - спектр исходного полимера, 2 - после облучения в воздухе в течение 6 h, 3 - после „травления“ образца 2 для удаления тонкого поверхностного слоя.

необлученному полимеру, хотя их частичная сшивка и увеличение содержание кислорода при УФ-облучении приводит к росту предела текучести и уменьшению пластичности образца в целом.

\section{Заключение}

В работе описано влияние УФ-облучения на деформационные характеристики при одноосном растяжении относительно нового термоэластопласта - синдиотактического 1,2-полибутадиена (СПБ). Установлено, что облучение УФ-светом приводит к некоторому упрочнению полимера, но одновременно снижается степень деформации до точки разрыва. Наряду с этим наблюдается увеличение молекулярной массы, резкое снижение растворимости и рост концентрации кислородных групп в СПБ. Подобное поведение связано с межмолекулярным сшиванием и одновременным окислением макромолекул при УФ-облучении. Последний процесс наиболее интенсивно идет в приповерхностном слое полимера. Такое гетерогенное окисление ответственно за то, что деформационные характеристики приповерхностного слоя существенно отличаются от объемных механических свойств.

Работа выполнена при частичной поддержке РФФИ (проект № 17-08-00974). В экспериментальных иссле- дованиях использовалось оборудование ЦКП Спектр ИФМК УФИЦ РАН, РЦКП АгидеЛЬ УФИЦ РАН и ЦКП „Наноструктурные материалы и высокие технологии“ УГАТУ. Авторы благодарят Каичева В.В. (ИК СО РАН) за съемку ряда РФЭС спектров.

\section{Список литературы}

[1] Drobny J.G. Handbook of thermoplastic elastomers. Elsevier, 2014. $441 \mathrm{p}$.

[2] Shanks R., Kong I. In Thermoplastic Elastomers / Ed. A.Z. ElSonbati. InTech. 2012. P. 137-155.

http://www.intechopen.com/books/thermoplasticelastomers/thermoplastic-elastomers

[3] Antony P., De S.K. // J. Macromol. Sci. Part C: Polym. Rev. 2001. Vol. 41. N 1-2. P. 41-77.

[4] Электронный ресурс. Режим доступа: http://www.jsr.co.jp/jsr_e/pd/tpe_rb.shtml

[5] Natta G., Corradini P. // J. Polymer Sci. 1956. Vol. 20. N 2. P. 251-266.

[6] Obata Y., Homma C., Tosaki C., Shiraishi N. // Polymer J. 1975. Vol. 7. N 2. P. 217-227.

[7] Chen Y., Yang D., Hu Y., Zhang X. // Cryst. Growth Design. 2004. Vol. 4. N 1. P. 117-121.

[8] Von Raven A., Heusinger H. // J. Polym. Sci. Polym. Lett. Ed. 1974. Vol. 12. N 10. P. 2255-2271.

[9] Okamoto H., Iwai T. // J. Appl. Polym. Sci. 1979. Vol. 23. N 6. P. 1893-1896. 
[10] Cai J., Yu Q., Zhang X., Lin J., Jiang L. // J. Polym. Sci. Part B. Polym. Phys. 2005. Vol. 43. N 20. P. 2885-2897.

[11] Чувыров А.Н., Кинзябулатов Р.Р., Лебедев Ю.А. // Доклады РАН. 2011. Т. 437. № 5. С. 659-662. [Chuvyrov A.N., Kinzyabulatov R.R., Lebedev Yu.A. // Doklady Chemistry. 2011. Vol. 437. N 2. P. 124-128.]

[12] Farber M., Worns J.R. // Patent USA 4394435. 1983.

[13] Чувыров А.Н., Терегулов Р.К. // Письма в ЖТФ. 2008. Т. 34. Вып. 17. C. 7-12. [Chuvyrov A.N., Teregulov R.K. // Tech. Phys. Lett. 2008. Vol. 34. N 9. P. 728-730.]

[14] Карлсон Т.А. Фотоэлектронная и оже-спектроскопия. М.: Мир, 1982. $286 \mathrm{c}$.

[15] Shirley D.A. // Phys. Rev. B. 1972. Vol. 5. N 12. P. 4709-4714.

[16] Хамидуллин А.Р., Чувыров А.Н., Лебедев Ю.А., Ситдиков В.Д. // Вестник МГУ. Сер. 3. Физика, Астрономия. 2013. № 3. C. 47-51. [Khamidullin A.R., Chuvyrov A.N., Lebedev Yu.A., Sitdikov V.D. // Moscow Univ. Phys. Bull. 2013. Vol. 68. N 3. P. 225-230.]

[17] Гиллет Дж. Фотофизика и фотохимия полимеров. М.: Мир, 1988. 435 c. [Guillet J. Polymer Photophysics and Photochemistry. Cambridge Univ. Press, 1985. 402 p.]

[18] Kagiya V.T., Takemoto K. // J. Macromol. Sci. A. 1976. Vol. 10. N 5. P. 795-810.

[19] Adam C., Lacoste J., Lemaire J. // Polym. Degrad. Stab. 1989. Vol. 26. N 3. P. 269-284.

[20] Clough R.L., Gillen K.T. // Polym. Degrad. Stab. 1992. Vol. 38. N 1. P. 47-56. 